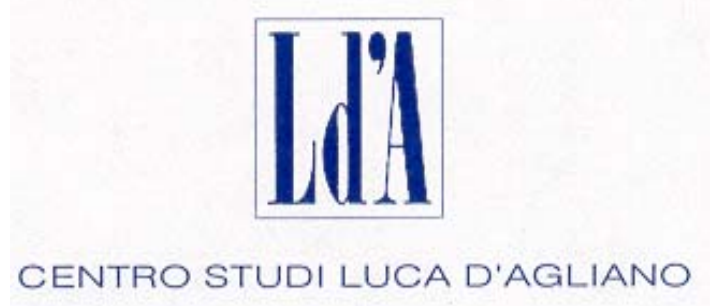

WWW.DAGLIANO.UNIMI.IT

\author{
CENTRO STUDI LUCA D'AGLIANO \\ DEVELOPMENT STUDIES WORKING PAPERS
}

N. 205

November 2005

Asylum Seekers in Europe: The Warm Glow of a Hot Potato

Giovanni Facchini*

Oliver Lorz**

Gerald Willmann***

* University of Illinois

** RWTH Aachen University

*** University of Kiel 


\title{
Asylum Seekers in Europe: The Warm Glow of a Hot Potato
}

\author{
Giovanni Facchini \\ Oliver Lorz \\ University of Illinois \\ RWTH Aachen University \\ Gerald Willmann* \\ University of Kiel
}

May 16, 2005

\begin{abstract}
The Common European Asylum System calls for increased coordination of the EU countries' policies towards asylum seekers and refugees. In this paper, we provide a formal analysis of the effects of coordination, explicitly modelling the democratic process through which policy is determined. In a symmetric, two-country citizen-candidate setup, in which accepting asylum seekers in one country generates a cross-border externality in the other, we show that coordination is desirable. Internalizing the externality leads to a welfare improvement over the non-cooperative outcome. However, contrary to suggestions by many observers, we show that allowing for cross-country transfers in the cooperative outcome leads to a welfare inferior outcome because the possibility of compensation exacerbates strategic delegation effects.

JEL-Codes: J61, H77, F22.

Keywords: Political Economy, Asylum Policy, Migration.
\end{abstract}

${ }^{*}$ Corresponding author: Department of Economics, Wilhelm-Seelig-Platz 1, CAU Kiel, 24098 Kiel, Germany; phone: +49 431 880-3354; fax: +49 431 880-3150; email: gerald@email.uni-kiel.de . We are grateful to Gil Epstein who provided the impetus for this research, to two anonymous referees for insightful comments, and to conference participants at the Midwest International Economics Spring 2005 meeting for helpful discussions. The usual caveat applies: all errors are ours. 


\section{Introduction}

Since the 1970's the EU has removed formal barriers to the internal mobility of production factors. At the same time, member countries have continued to follow autonomous policies towards immigration from the rest of the world. The "Single European Act', which established the Single Market, went as far as explicitly specifying that "nothing in these provisions shall affect the right of member states to take measures as they consider necessary for the purpose of controlling immigration from third countries." 1

Retaining control over immigration policy is of utmost political concern to most countries. Indeed, as recent Eurobarometer surveys show, a majority of EU citizens consistently opposes the idea of delegating authority over the issue to Brussels, ${ }^{2}$ and the successful anti-immigration campaigns of a Pim Fortuyn or Jörg Haider only confirm the importance of this policy dimension. At the same time, the efforts towards the creation of a pan-European labor market and the removal of border controls between EU countries have made it difficult to enforce limits on the mobility of third country nationals within the EU. Furthermore, there is a serious risk of underprovision of border controls by those EU member countries that are not likely to be the final destination of immigration flows. ${ }^{3}$ For these reasons, many observers have suggested that coordinating migration policies might actually be desirable. ${ }^{4}$

While the EU is far from having a common immigration policy, the debate has led to the adoption of a series of initiatives aimed at increasing the coordination of the actions of the member countries (Schengen accords), but with only limited impact on the integration of labor markets. A more substantial step is the proposed establishment of a Common European Asylum System. This initiative has so far led to two directives, spelling out a precise definition of refugees, as well as some minimum standards concerning the status of refugees as well as asylum procedures and reception

\footnotetext{
${ }^{1}$ General Declaration on Articles 13 to 19 .

${ }^{2}$ See Luedtke (2005).

3 "Switzerland and Austria have accused Italy of turning a blind eye to would-be refugees heading north." The Economist, September 62001.

${ }^{4}$ See for instance Boeri, Hanson, and McCormick (2002), Hatton and Williamson (2004), and Hatton (2004).
} 
conditions for asylum seekers. Many observers suggest that these first steps are not sufficient, and recommend a more substantial effort towards further coordination. For instance, Boeri, Hanson, and McCormick (2002) propose to "... coordinate the implementation of the rules, and share the costs of humanitarian migration equally, for example by a fund for asylum seekers, refugees and other humanitarian migrants. ${ }^{5}$ This will internalize costs and prevent countries with more generous policies from being penalized."

While standard welfare economics seems to support this idea, the purpose of our paper is to address the desirability of coordination when the democratic process through which migration policies are decided is explicitly taken into account. To this end, we develop a symmetric, two-country model in which an inflow of foreigners in one country gives rise to a positive externality on the residents of the other. Policy is determined through a two-stage process: In the first stage, citizens elect a representative, while in the second stage the representatives determine immigration policy. ${ }^{6}$ We compare the outcome without coordination to two possible scenarios in which countries cooperate: In the first, no transfer payments between countries are possible, whereas in the second transfer payments are possible, as has been suggested in the recent debate.

We find for both scenarios that taking into account the democratic process does not alter the main conclusion that there are gains from policy coordination. However, because of strategic delegation, the utilitarian optimum is not achieved. Interestingly, allowing for transfers between countries leads to an outcome which is inferior to the situation without transfers. The intuition for this result is that the possibility of direct cost sharing will exacerbate the strategic delegation emerging in the political game, implying an inefficiently low level of immigration. From a normative perspective, our analysis suggests that while some coordination might be desirable, very pervasive approaches can lead to less attractive outcomes. With asymmetric preferences for

\footnotetext{
${ }^{5}$ Emphasis added by the authors.

${ }^{6}$ The citizen-candidate framework we are using has been introduced by Besley and Coate (1997) and Osborne and Slivinski (1996). The concept of strategic delegation has been applied in different contexts: Besley and Coate (2003) use it to analyze the provision of local public goods, Willmann (2004) employs it to endogenize trade policy, Lorz and Willmann (2005) explain the degree of regionalism in this way, etc.
} 
immigration, we show the additional presence of the usual beneficial role of sidepayments as they allow an efficient allocation of asylum seekers.

The existing literature on policy towards asylum seekers has emphasized the risk of a 'race to the bottom', i.e. a tendency for those countries with more generous provisions towards refugees to adopt more restrictive policies in order to avoid becoming asylum magnets. Noll (2000) has even talked of a 'common market of deflection' within the European Union. While the issue has spurred a lively debate in the media, it has attracted relatively little formal analysis. In two recent papers, Hatton (2004) and Hatton and Williamson (2004) have developed a formal framework that highlights how policy coordination might be desirable from the point of view of welfare maximization. The key driving force behind their results is the existence of positive spill-overs between countries, rather than the internalization of deflection effects. Our analysis also emphasizes the public good nature of public policy towards asylum seekers; however, we move beyond simple welfare maximization and model explicitly the role of the democratic process in shaping policy.

The remainder of the paper is organized as follows. Section 2 reviews the recent developments in the inflows of asylum seekers in the EU and the policy stances adopted by the member countries. We then introduce the model used for our analysis and discuss the social planner solution as a benchmark case against which to evaluate the endogenous policy outcomes. In Section 4, we determine the endogenous migration policy adopted when countries do not cooperate. The outcome with coordination is discussed in Section 5, where we consider first the situation without transfers between countries, and subsequently allow for explicit cost sharing. Section 6 explores the case of asymmetric preferences for asylum seekers before we offer concluding remarks in Section 7.

\section{Asylum seekers and policies}

In 2002, about two thirds of all asylum applications in the western world were directed at the EU-15 member countries (UNHCR (2003)). The number of asylum seekers trying to enter the EU-15 has increased dramatically over the past twenty years, 


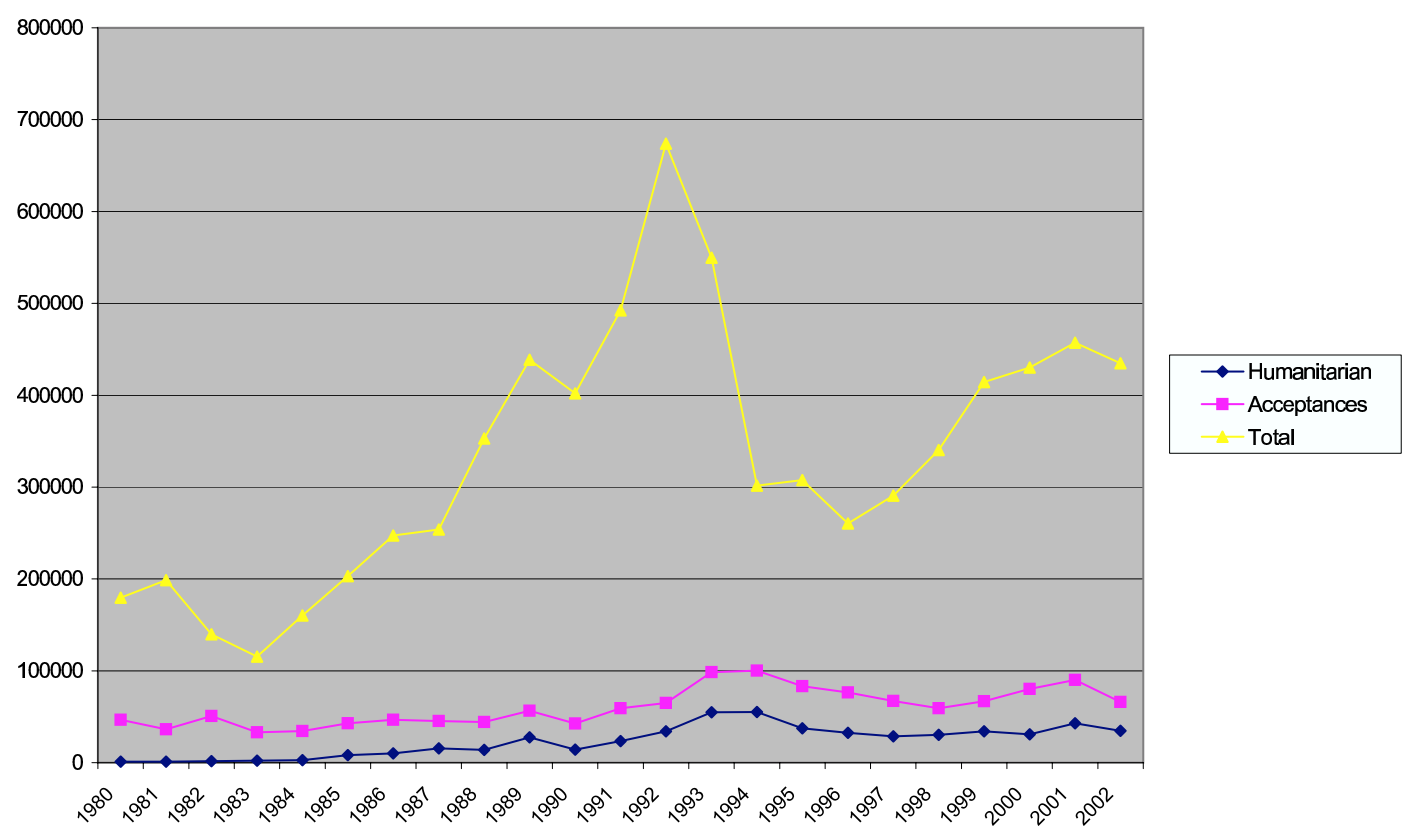

Figure 1: Asylum applications approval. (Source: Eurostat)

peaking in the aftermath of the fall of the iron curtain at around 700,000 in 1992. By 2002, a little over 400,000 applications were filed, a figure that is still more than twice as high as the level of the 1980's (see Figure 1). Notwithstanding these fluctuations in the flow of asylum seekers, the number of applications that were actually accepted based on the Geneva convention has remained relatively stable at around 38,000 a year, while the number of refugees admitted on humanitarian grounds has increased substantially over the period, accounting for about half of the total admissions in 2002. The main message that emerges from Figure 1 is that while the number of applications has experienced a substantial upward trend, the number of positive decisions has not increased proportionally, implying that policy towards asylum seekers has become more restrictive over time. What lies behind this development?

We can distinguish two components of a EU country's policy towards asylum seekers: a supra-national component and a national one. The supra-national dimension is due to the Geneva Convention Relating to the Status of Refugees. The document, agreed upon in 1951, defines a refugee as someone who is outside his country of origin, and is unable or unwilling to return to it (Art. 1). It also establishes the principle 
of non refoulement, which means that the refugee cannot be forcibly returned to the frontier of a territory where her life or freedom would be threatened (Art. 33). By 1978, all EU-15 members had ratified the Geneva convention and this agreement represents the basic legal foundation of the EU's policy towards asylum seekers. The growing number of refugees during the eighties led to an effort to harmonize the rules and the policies followed by member states. Particular emphasis was put on the harmonization of visa policies and the establishment of sanctions against carriers that illegally transport refugees. In 1990, the Dublin Convention sought to put an end to the so called 'asylum shopping' phenomenon, decreeing that the application for asylum should be dealt with by one state only, usually the state of first entry. The subsequent London resolution established a series of important, though non-binding principles: First the concept of a 'safe third country', allowing refusal of admission if the refugee had gone through a safe third country. Second, 'manifestly unfounded' claims could be rejected without the right to appeal. Third, a list of 'safe countries of origin' was drawn up, with the presumption that no serious risk would be incurred by the claimant were she to be expelled and repatriated to a country on that list.

The most recent developments stem from the Amsterdam Treaty and the Tampere 1999 European Council. Consequently, as of 2002, the EU Commission has the sole right to propose legislation and two further directives were adopted: The first one, introduced in March 2003, specifies 'Minimum standards for the qualifications and the status of asylum seekers in the EU' and the second, adopted in April 2004, deals with 'Minimum standards for the qualifications and status of third country nationals and stateless persons as refugees or as persons who otherwise need international protection'. The intention has been to increase the coordination of the policies pursued by the various EU-15 countries. Along the same lines, a European Refugee Fund was established in 2000. Endowed with 216 million Euros for the period 2000-2004, the fund aims at providing financial support to help the member states receive asylum seekers, refugees and displaced persons.

Table 2, taken from Hatton (2004), gives us an idea of the evolution of the policy towards asylum seekers followed by each of the EU-15 countries. The indeces we report are intended to capture changes of the respective policies. A value of 1 indi- 


\begin{tabular}{|lcccc|}
\hline & $\begin{array}{c}\text { Access } \\
\text { index }\end{array}$ & $\begin{array}{c}\text { Procedure } \\
\text { index }\end{array}$ & $\begin{array}{c}\text { Outcomes } \\
\text { index }\end{array}$ & $\begin{array}{c}\text { Conditions } \\
\text { index }\end{array}$ \\
\hline Austria & 1.43 & 1.46 & 1.9 & 1.57 \\
Belgium & 0.47 & 2.4 & 1.86 & 1.6 \\
Denmark & 1 & 2.5 & 1.9 & 2 \\
Finland & 1 & 2.3 & 1.68 & 1.16 \\
France & 1.48 & 1.33 & 1.8 & 1.48 \\
Germany & 1.65 & 1.95 & 1.8 & 2.1 \\
Greece & 0 & 1.25 & 1.9 & 2.8 \\
Ireland & 0.2 & 0.53 & 0.7 & 0.96 \\
Italy & 1.92 & 1.92 & 0.5 & 1.72 \\
Netherlands & 1.02 & 1.57 & 1.53 & 1.7 \\
Portugal & 1 & 1.13 & 1.62 & 2 \\
Spain & 1.58 & 1.08 & 1.69 & 2 \\
Sweden & 1 & 1.74 & 2.48 & 1.1 \\
UK & 1 & 1.8 & 1.02 & 2.09 \\
\hline
\end{tabular}

Table 1: Changes in asylum policies 1990-1999. (Source: Hatton (2004))

cates the introduction of a more restrictive policy, whereas a value of 0 means that no major change was introduced that year. Each 'policy' stance involves multiple possible dimensions. For instance, in the construction of the procedure index Hatton (2004) considered the introduction of 'safe third country' provisions, rules concerning 'manifestly unfounded claims' and 'fast track procedures'. 7 The reported indeces are averages over the 1990-1999 period. While the construction of these indicators necessarily involves some arbitrariness, the main message is clear: All countries have moved towards more restrictive policies, with the possible exception of Ireland, where the government's attitude seems not to have changed much.

Even though the policy stance adopted by the various countries has moved in the same direction and a substantial effort has been profused towards coordinating policies, when it comes to the actual acceptance of asylum seekers, we see from Figure 2 that there are still considerable differences across countries. The data are taken from Eurostat and represent the share of all asylum seeking applications that are accepted. As we can see, the Northern countries (Sweden and Finland, in particular,

\footnotetext{
${ }^{7}$ For more details on the construction of the figures, we refer the reader to the Appendix of Hatton (2004).
} 


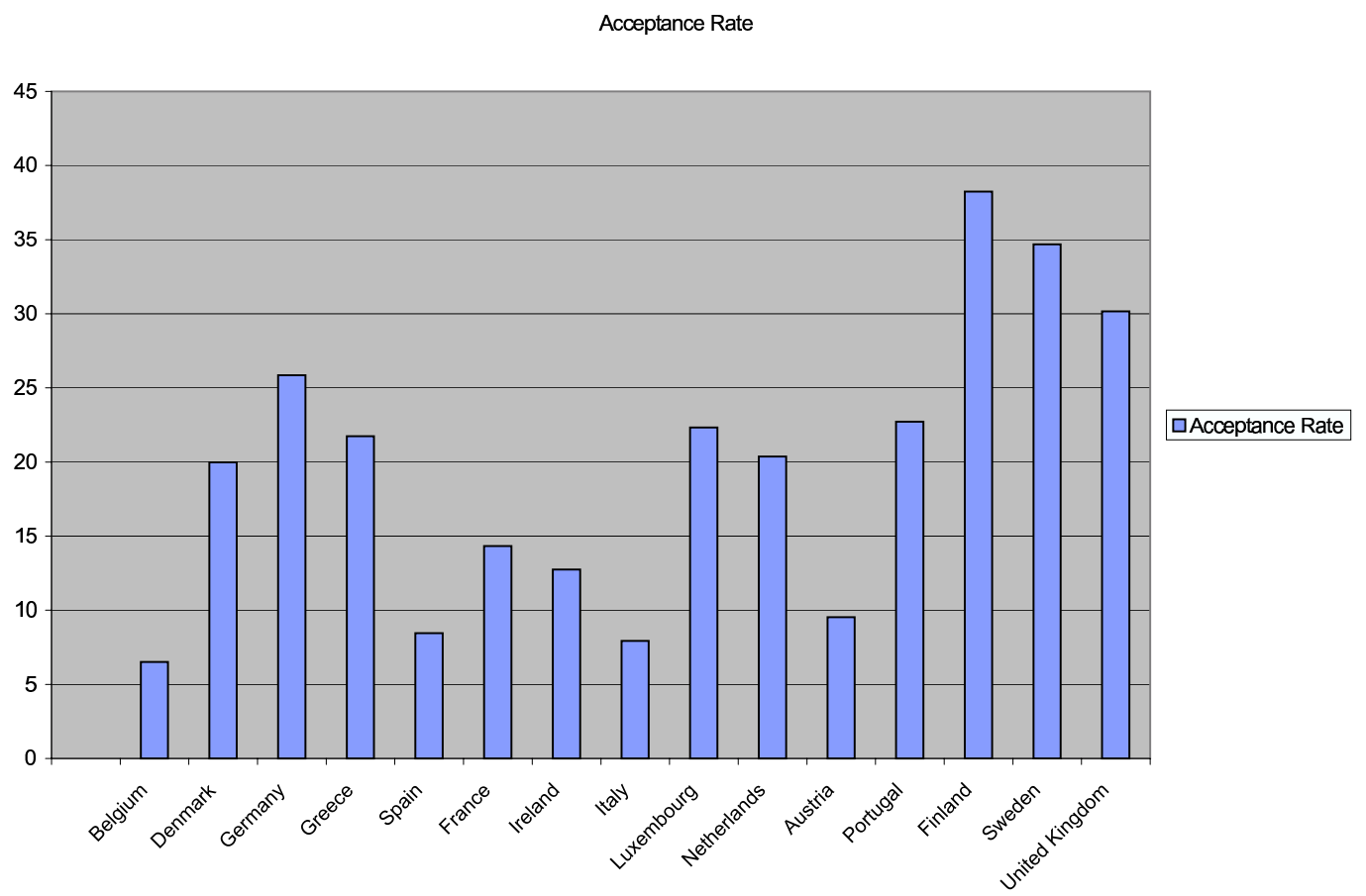

Figure 2: Asylum applications approval. (Source: Eurostat)

and to a lesser extent Denmark) seem to be much more receptive than Belgium, Italy, or Austria. While there may be many reasons behind these differences, it is fair to say that the efforts at coordinating asylum policy undertaken so far have produced only very limited results. In the remainder of this paper, we will discuss to what extent policy coordination is desirable, once due attention is paid to the democratic process that determines such policies.

\section{The Model}

We consider two symmetric countries, indexed by $i \in\{1,2\}$. Each country is populated by a continuum of citizens, and we normalize the mass of each population to one. Refugees coming from the rest of the world can be admitted into either country. We denote by $m_{i}$ the number of asylum seekers allowed into country $i$. Note that, due to the above normalization, $m_{i} \in(0,1)$ indicates the number of asylum seekers as a fraction of the domestic population. Country $i$ controls the access to its territory and can therefore choose $m_{i}$; similarly the other country determines $m_{-i}$. 
Let the vector $m=\left(m_{1}, m_{2}\right)$ summarize the policies followed by the two countries. The residents of country $i$ derive an altruistic benefit from admitting refugees into either country. We denote this benefit by $B_{i}\left(\sum_{j} m_{j}\right)$ and note that it depends on the total number admitted into both countries. The same effect has been pointed out by Hatton and Williamson (2004). It captures the warm glow of helping refugees to avoid their plight elsewhere and enjoy safe haven in either country. Clearly, there are also costs from admitting asylum seekers which we denote by $C_{i}\left(m_{i}, m_{-i}\right)$. In the interest of tractability, we assume that the benefit to country $i$ takes the form $B_{i}=(1+\alpha) \sum_{j} m_{j}$ and that the cost amounts to $C_{i}=-\ln \left(1-\lambda m_{i}-[1-\lambda] m_{-i}\right)$, where $1 / 2<\lambda<1 .{ }^{8}$ While the cost to country $i$ is primarily determined by the number of refugees it accepts $\left(m_{i}\right)$, we do allow for cost spill-overs from the inflow $\left(m_{-i}\right)$ into the other country. ${ }^{9}$ These spill-overs can, for example, be due to a permeable, imperfectly controlled interior border between the two countries. In this case $\lambda$ should be thought of as the fraction of immigrants admitted by country $i$ who choose country $i$ as their final destination, whereas $1-\lambda$ is the fraction of the immigrants admitted by country $i$ who end up moving to the other country. ${ }^{10}$ In addition to this interpretation, our formulation also allows us to capture pecuniary spill-overs, for example, from wage effects in one country's labor market onto the other's due to the free mobility of native workers between the two countries member of the EU.

Following these assumptions, the utility of individual $\alpha_{i}$ in country $i$ takes the following form:

$$
U_{i}\left(\alpha_{i}, m\right)=\left[1+\alpha_{i}\right]\left[m_{i}+m_{-i}\right]+\ln \left(1-\lambda m_{i}-[1-\lambda] m_{-i}\right)
$$

where $\alpha_{i}$ represents the strength of the individual's altruistic preference for admit-

\footnotetext{
${ }^{8}$ It is worth emphasizing that the specific functional forms are chosen solely to guarantee a closedform solution. The crucial features of this setup are the convex cost that gives rise to a concave objective function and the positive net spill-over from admitting asylum seekers. A similar functional form is used by Segendorff (1998).

${ }^{9}$ Conceptionally, we can distinguish up-front processing costs and the ongoing cost burden. While our model allows for both, the inclusion of spill-overs is relevant mainly for the latter.

${ }^{10}$ Notice that in our model we do not explicitly consider the dynamic adjustments involved in the 'relocation' of migrants across countries. This is realistic as long as the relocation takes place quickly. Alternatively, as suggested by one referee, we could think of $m_{i}$ as representing the stock of refugees, and the costs and utilities should then be interpreted as present values.
} 
ting refugees. We assume that citizens within both countries differ with respect to this preference term, i.e. in either country $\alpha_{i}$ follows the same well-behaved density function with mean and median $\bar{\alpha}$.

As a normative benchmark for our analysis, we start by deriving the values for $m_{i}$ and $m_{-i}$ that maximize the combined welfare of both countries. This is the policy vector a social planner who weighs the utility of all individuals in both countries equally would set. ${ }^{11}$ Thus, we are seeking the solution to the following problem:

$$
\max _{m_{1}, m_{2}} W=U_{1}(\bar{\alpha}, m)+U_{2}(\bar{\alpha}, m)
$$

The corresponding first order conditions are:

$$
2+2 \bar{\alpha}-\frac{\lambda}{1-\lambda m_{i}-[1-\lambda] m_{-i}}-\frac{1-\lambda}{1-\lambda m_{-i}-[1-\lambda] m_{i}}=0 .
$$

Taken together, the first order conditions of both countries imply that the number of refugees admitted into each country is the same, i.e. $m_{i}=m_{-i}$. This common number amounts to:

$$
m_{i}^{U}(\bar{\alpha})=\frac{1+2 \bar{\alpha}}{2+2 \bar{\alpha}}
$$

the level of immigration that maximizes utilitarian social welfare. This is the level that we will use as a reference point to determine the welfare properties of the political equilibria we will examine next.

\section{Immigration Levels without Coordination}

In this section, we consider the scenario where each country determines the number of refugees to admit non-cooperatively. Within each country, the decision is taken following a two-stage political process. In the first stage, citizens elect a representative. In the second stage, each region's representative decides on the level of refugees to admit, $m_{i}$, taking the level in the other region, $m_{-i}$, as given. Both representatives

\footnotetext{
${ }^{11}$ Note that the welfare of immigrants enters aggregate welfare in each country only indirectly through the warm glow effect.
} 
are assumed to be citizen-candidates in the sense of having the personal preferences of an ordinary citizen. That is, the representative of region $i$ has a preference $\hat{\alpha}_{i}$ for immigration, and the vector $\hat{\alpha}$ represents the preference profile of the representatives in the two regions. In the remainder of the paper we will use 'hats' to indicate the preferences of representatives. In order to look for the non-cooperative outcome we solve the game backwards. That is, we start by analyzing first the second stage, where the representative chooses the number of refugees. Taking the identity of representative $i$ as given (for the time being), the first order condition of her maximization problem takes the following form:

$$
1+\hat{\alpha}_{i}-\frac{\lambda}{1-\lambda m_{i}-[1-\lambda] m_{-i}}=0
$$

Solving this equation for $m_{i}$, we obtain the reaction function of each representative:

$$
m_{i}=\frac{1+\hat{\alpha}_{i}-\lambda}{\lambda\left[1+\hat{\alpha}_{i}\right]}-\frac{1-\lambda}{\lambda} m_{-i}
$$

As can be seen from the coefficient in front of $m_{-i}$, the immigration levels are strategic substitutes. In other words, the higher the number of asylum seekers admitted by the other country, the lower is the number of refugees country $i$ decides to accept, because country $i$ 's representative already benefits from the refugees the other country lets in. Solving for the Nash equilibrium, we find that the equilibrium immigration levels $m_{i}^{N}(\hat{\alpha})$ are given by:

$$
m_{i}^{N}(\hat{\alpha})=\frac{\lambda\left[1+\hat{\alpha}_{i}-\lambda\right]}{[2 \lambda-1]\left[1+\hat{\alpha}_{i}\right]}-\frac{[1-\lambda]\left[1+\hat{\alpha}_{-i}-\lambda\right]}{[2 \lambda-1]\left[1+\hat{\alpha}_{-i}\right]} .
$$

Note that these non-cooperative levels depend on the identity of both representatives. Straightforward comparative statics reveals that an increase in $\hat{\alpha}_{i}$ raises the immigration level in country $i$ but lowers the immigration level in the other country. More 
formally: $:^{12}$

$$
\begin{aligned}
\frac{d m_{i}^{N}}{d \hat{\alpha}_{i}} & =\frac{\lambda^{2}}{\left[1+\hat{\alpha}_{i}\right]^{2}[2 \lambda-1]}>0, \\
\frac{d m_{-i}^{N}}{d \hat{\alpha}_{i}} & =-\frac{\lambda[1-\lambda]}{\left[1+\hat{\alpha}_{i}\right]^{2}[2 \lambda-1]}<0 .
\end{aligned}
$$

The effect of the own representative is intuitively clear: the more inclined is the representative towards immigration, the more refugees she admits. The negative effect of the other country's represenative stems from the own effect and the strategic substitutability that we established above. In a symmetric equilibrium with both representatives having the same preference, equation (7) simplifies to

$$
m_{i}^{N}(\hat{\alpha})=\frac{1+\hat{\alpha}_{i}-\lambda}{1+\hat{\alpha}_{i}} \quad \text { for } \quad \hat{\alpha}_{i}=\hat{\alpha}_{-i}
$$

We are now ready to analyze the first stage of the game, taking into account what we already know about the second stage. The citizens in each country elect their representative so as to maximize their utility imputation $U_{i}\left(\alpha_{i}, m^{N}(\hat{\alpha})\right)$, where $m^{N}\left(\hat{\alpha}_{i}\right)$ is given by equation (7) above. The corresponding first order condition takes the form:

$$
\left[1+\alpha_{i}\right]\left[\frac{d m_{i}^{N}}{d \hat{\alpha}_{i}}+\frac{d m_{-i}^{N}}{d \hat{\alpha}_{i}}\right]-\frac{\lambda d m_{i}^{N} / d \hat{\alpha}_{i}+[1-\lambda] d m_{-i}^{N} / d \hat{\alpha}_{i}}{1-\lambda m_{i}(\hat{\alpha})-[1-\lambda] m_{-i}(\hat{\alpha})}=0
$$

Inserting for $d m_{i}^{N} / d \hat{\alpha}_{i}, d m_{-i}^{N} / d \hat{\alpha}_{i}, m_{i}(\hat{\alpha})$, and $m_{-i}(\hat{\alpha})$ from above, and focusing on a symmetric solution (i.e. $\hat{\alpha}_{i}=\hat{\alpha}_{-i}$ ), we can rewrite (11) as follows:

$$
\frac{\alpha_{i}-\hat{\alpha}_{i}}{1+\hat{\alpha}_{i}}=\frac{1-\lambda}{\lambda}
$$

Since the right hand side is positive, because $\lambda<1$, we see that each voter prefers a representative with a lower preference for immigration than she has herself, i.e. $\hat{\alpha}_{i}<$ $\alpha_{i}$. This holds a fortiori for the median voter who determines the election outcome. The median voter with $\alpha_{i}=\bar{\alpha}$ strategically delegates to a representative with $\hat{\alpha}_{i}<\bar{\alpha}$.

\footnotetext{
${ }^{12}$ Recall that we assume $1 / 2<\lambda<1$.
} 
In other words, the elected representatives in equilibrium have a lower preference for immigration $\hat{\alpha}_{i}^{N}$ than the respective median. We have therefore established the following result:

Proposition 1 Strategic delegation worsens the problem of non-cooporative decisionmaking:

$$
m_{i}^{N}\left(\hat{\alpha}^{N}\right)<m_{i}^{N}(\bar{\alpha})<m_{i}^{U}(\bar{\alpha})
$$

As it turns out, the number of refugees accepted in the non-cooperative equilibrium is suboptimally low for two reasons: First, because the net positive spill-overs are not internalized. Second, because the median voter strategically delegates to someone with a lower preference for immigration. ${ }^{13}$

\section{Policy Coordination}

We now turn our attention to the case where the two countries cooperate. Again, we envisage a two-stage political process, similar to the one in the previous section, only that now the two representatives cooperatively choose the migration vector into either country in the second stage. This approach is intended to provide a stylized model of the Common European Asylum System. We distinguish further between the case in which transfers between countries are not permitted and the case in which cost sharing is instead allowed. We begin by discussing the former case, while the analysis of the latter is conducted in the second subsection.

\subsection{Without Cost Sharing}

Consider the case in which the two representatives cooperatively decide on the migration levels and the cost of the policy is borne by each country without the possibility of side-payments. We model coordination by assuming that in the second

\footnotetext{
${ }^{13}$ Note that in the absence of cost spill-overs $(\lambda=1)$ strategic delegation would disappear in the non-cooperative game. This is not true in the coordination case because there strategic delegation is undertaken for different reasons, as will become clear in the next section.
} 
stage the two representatives engage in a Nash-bargaining game. They seek to maximize the Nash-product $N=s_{1} \cdot s_{2}$, where the surplus from bargaining $s_{i}$ is given by $s_{i}=\left[1+\hat{\alpha}_{i}\right]\left[m_{i}+m_{-i}\right]+\ln \left(1-\lambda m_{i}-[1-\lambda] m_{-i}\right)-U_{i}\left(\hat{\alpha}_{i}, m^{N}\left(\hat{\alpha}^{N}\right)\right)$ and where $U_{i}\left(\hat{\alpha}_{i}, m^{N}\left(\hat{\alpha}^{N}\right)\right)$ in turn denotes the outside utility of representative $i$ if no agreement is reached. In other words, if this happens we assume that the non-cooperative migration levels of the previous section are implemented. ${ }^{14}$

The maximization of the Nash-product yields the following first order conditions:

$$
\begin{aligned}
\left\{1+\hat{\alpha}_{i}-\frac{\lambda}{1-\lambda m_{i}-[1-\lambda] m_{-i}}\right\} & s_{-i}+ \\
& \left\{1+\hat{\alpha}_{-i}-\frac{1-\lambda}{1-\lambda m_{-i}-[1-\lambda] m_{i}}\right\} s_{i}=0 .
\end{aligned}
$$

These first order conditions implicitly determine the immigration levels in the bargaining equilibrium without side-payments, $m_{i}^{B}(\hat{\alpha})$ and $m_{-i}^{B}(\hat{\alpha})$, as functions of the identity of the two representatives. Focusing again on a symmetric equilibrium where both representatives have the same preference for immigration, we obtain from (14) that $m_{1}^{B}=m_{2}^{B}$ and in particular:

$$
m_{i}^{B}(\hat{\alpha})=\frac{1+2 \hat{\alpha}_{i}}{2+2 \hat{\alpha}_{i}} \quad \text { for } \quad \hat{\alpha}_{i}=\hat{\alpha}_{-i}
$$

Note that this solution resembles the utilitarian optimum of section 3 . However, $\hat{\alpha}_{i}$ may well differ from the preference parameter $\bar{\alpha}$ of the average citizen. To derive the equilibrium $\hat{\alpha}_{i}$ we now turn to the election stage of the model. As in the previous section, each voter in country $i$ choses $\hat{\alpha}_{i}$ to maximize $U_{i}\left(\alpha_{i}, m^{B}(\hat{\alpha})\right)$, with $m_{i}^{B}(\hat{\alpha})$ and $m_{-i}^{B}(\hat{\alpha})$ determined implicitly by equation (14) above. The first-order condition of the voter's maximization problem takes the form:

$$
\left[1+\alpha_{i}\right]\left[\frac{d m_{i}^{B}}{d \hat{\alpha}_{i}}+\frac{d m_{-i}^{B}}{d \hat{\alpha}_{i}}\right]-\frac{\lambda d m_{i}^{B} / d \hat{\alpha}_{i}+[1-\lambda] d m_{-i}^{B} / d \hat{\alpha}_{i}}{1-\lambda m_{i}^{B}(\hat{\alpha})-[1-\lambda] m_{-i}^{B}(\hat{\alpha})}=0 .
$$

\footnotetext{
${ }^{14}$ The outside utility thus takes the form $U_{i}\left(\hat{\alpha}_{i}, m^{N}\right)=2\left[1+\hat{\alpha}_{i}\right] m_{i}^{N}\left(\hat{\alpha}^{N}\right)+\ln \left(1-m_{i}^{N}\left(\hat{\alpha}^{N}\right)\right)$ where $m_{i}^{N}\left(\hat{\alpha}^{N}\right)$ is determined by the equilibrium without coordination derived in the previous section. Note that this implies that the representatives who bargain are not necessarily the same as those who set the immigration level non-cooperatively. We make this assumption to keep the model tractable.
} 
With symmetry $\left(\hat{\alpha}_{i}=\hat{\alpha}_{-i}\right)$, the marginal influence of $\hat{\alpha}_{i}$ on $m_{i}^{B}$ and $m_{-i}^{B}$ can be written as (see the appendix for a derivation):

$$
\begin{aligned}
\frac{d m_{i}^{B}}{d \hat{\alpha}_{i}} & =\frac{\left[1+s_{i}\right][2 \lambda-1]+2\left[1+\hat{\alpha}_{i}\right]\left[m_{i}^{B}(\hat{\alpha})-m_{i}^{N}\left(\hat{\alpha}^{N}\right)\right]}{4[2 \lambda-1]\left[1+\hat{\alpha}_{i}\right]^{2}\left[1+s_{i}\right]} \\
\frac{d m_{-i}^{B}}{d \hat{\alpha}_{i}} & =\frac{\left[1+s_{i}\right][2 \lambda-1]-2\left[1+\hat{\alpha}_{i}\right]\left[m_{i}^{B}(\hat{\alpha})-m_{i}^{N}\left(\hat{\alpha}^{N}\right)\right]}{4[2 \lambda-1]\left[1+\hat{\alpha}_{i}\right]^{2}\left[1+s_{i}\right]}
\end{aligned}
$$

In equilibrium, the median voter determines the election outcome. Setting $\hat{\alpha}_{i}=\bar{\alpha}$ and inserting the above expressions for $d m_{i}^{B} / d \hat{\alpha}_{i}$ and $d m_{-i}^{B} / d \hat{\alpha}_{i}$ and (15) for $m_{i}^{B}(\hat{\alpha})$ and $m_{-i}^{B}(\hat{\alpha})$ into equation (16), we obtain:

$$
\frac{\bar{\alpha}-\hat{\alpha}_{i}^{B}}{\left(1+\hat{\alpha}_{i}^{B}\right)^{2}}=\frac{2\left[m_{i}^{B}\left(\hat{\alpha}^{B}\right)-m_{i}^{N}\left(\hat{\alpha}^{N}\right)\right]}{1+s_{i}}
$$

Since $m_{i}^{N}(\bar{\alpha})$ is less than $m_{i}^{U}(\bar{\alpha})$ due to the presence of the externality which is not internalized in the non-cooperative outcome and because $m_{i}^{B}(\bar{\alpha})=m_{i}^{U}(\bar{\alpha})$, we know that $m_{i}^{B}(\bar{\alpha})>m_{i}^{N}(\bar{\alpha}) .{ }^{15}$ Equation (19) then can only be satisfied if $\hat{\alpha}_{i}^{B}<\bar{\alpha}$ and $m_{i}^{B}\left(\hat{\alpha}^{B}\right)>m_{i}^{N}\left(\hat{\alpha}^{N}\right)$. The political outcome under cooperation thus entails strategic delegation as before since the median voter chooses a representative with $\hat{\alpha}_{i}^{B}<\bar{\alpha}$. We can therefore conclude that:

Proposition 2 The number of refugees admitted under cooperation without transfer payments is higher than without cooperation at all, but is still inefficiently low, i.e.

$$
m_{i}^{N}\left(\hat{\alpha}^{N}\right)<m_{i}^{B}\left(\hat{\alpha}^{B}\right)<m_{i}^{U}(\bar{\alpha})
$$

The last result tells us that the strategic delegation effect alone is not sufficient to lower the equilibrium immigration levels to a level which is as inefficiently low as the one prevailing in the non-cooperative outcome. The reason is that while in both cases we do have strategic delegation, the positive net spill-overs are ignored under the non-cooperative regime, but are internalized if cooperation is possible. From a policy perspective, the implication is that the push towards increased coordination

\footnotetext{
${ }^{15}$ Note that this argument would hold even if there were no strategic delegation in the noncooperative game the of previous section.
} 
in the determination of asylum policy is desirable, even if we take account of the democratic process through which the policy itself is determined.

In the following subsection, we analyze the extent to which coordination is desirable, i.e. whether a further deepening of policy coordination is going to lead to further welfare gains.

\subsection{With Cost Sharing}

We now extend the analysis by allowing countries to share the cost of the migration policies. That is, we no longer assume that each country pays the costs of its own refugees. Instead, the representatives bargain not only over immigration levels but also over how to share the cost. In particular, we allow for a side-payment $Z$ that country 2 pays to country 1 , or vice versa if $Z$ is negative. As in the previous subsection, we assume that the two representatives engage in Nash-bargaining. The Nash-product now takes the form $N=\left(s_{1}+Z\right)\left(s_{2}-Z\right)$. To maximize this Nashproduct with side payments, we proceed in two steps: first, we derive the immigration levels $m_{i}^{S}$ and $m_{-i}^{S}$ that maximize the aggregate bargaining surplus $s_{1}+s_{2}$; second, we determine $Z^{S}=\left[s_{2}-s_{1}\right] / 2$, which divides the bargaining surplus equally between the two countries.

The first order conditions for $m_{i}^{S}$ and $m_{-i}^{S}$ take the following form:

$$
2+\hat{\alpha}_{i}+\hat{\alpha}_{-i}-\frac{\lambda}{1-\lambda m_{i}-[1-\lambda] m_{-i}}-\frac{1-\lambda}{1-\lambda m_{-i}-[1-\lambda] m_{i}}=0 .
$$

These equations are similar to the ones we derived for the utilitarian social optimum, only that here we still have to determine the identity of the respective representatives.

As in the utilitarian optimum, both equations in (21) taken together imply that $m_{i}^{S}=m_{-i}^{S}$. In particular, the immigration levels amount to:

$$
m_{i}^{S}(\hat{\alpha})=m_{-i}^{S}(\hat{\alpha})=\frac{1+\hat{\alpha}_{i}+\hat{\alpha}_{-i}}{2+\hat{\alpha}_{i}+\hat{\alpha}_{-i}}
$$

The equilibrium side payment that distributes the surplus equally then takes the 
form:

$$
Z^{S}\left(\hat{\alpha}, m^{S}(\hat{\alpha})\right)=\left[\hat{\alpha}_{2}-\hat{\alpha}_{1}\right]\left[m_{i}^{S}(\hat{\alpha})-m_{i}^{N}\left(\hat{\alpha}^{N}\right)\right]
$$

We can now analyze the first stage of the game, in which elections take place. Voters seek to maximize their utility imputation

$$
U_{i}\left(\alpha_{i}, m^{S}, Z^{S}\right)=2\left[1+\alpha_{i}\right] m_{i}^{S}+\ln \left(1-m_{i}^{S}\right) \pm Z^{S}
$$

where $m_{i}^{S}=m_{i}^{S}(\hat{\alpha})$ is given by (22) and $Z^{S}=Z^{S}\left(\hat{\alpha}, m^{S}(\hat{\alpha})\right)$ is given by (23). Solving for the symmetric equilibrium, the first order condition of the median voter's problem can be written as follows:

$$
\frac{\bar{\alpha}-\hat{\alpha}_{i}^{S}}{\left(1+\hat{\alpha}_{i}^{S}\right)^{2}}=2\left[m_{i}^{S}\left(\hat{\alpha}^{S}\right)-m_{i}^{N}\left(\hat{\alpha}^{N}\right)\right]
$$

As in the previous subsection, this result implies strategic delegation. Again, we can see that the number of asylum seekers admitted by each country continues to be inefficiently low, but higher than in the non-cooperative case. This implies that some form of cooperation, whether with or without transfers between countries, is desirable from the point of welfare maximization, even if explicitly account is taken of the political process leading to the decision on the number of refugees to be admitted.

The question left to answer is how the outcome with side-payments compares to the case in which countries are not allowed to carry out side-payments. Inserting $m_{i}=\left[1+2 \hat{\alpha}_{i}\right] /\left[2+2 \hat{\alpha}_{i}\right]$ into (19) and (25) and rearranging yields:

$$
\begin{aligned}
\frac{\bar{\alpha}-\hat{\alpha}_{i}^{B}}{\left[1+\hat{\alpha}_{i}^{B}\right]\left\{1+2 \hat{\alpha}_{i}^{B}-2\left[1+\hat{\alpha}_{i}^{B}\right] m^{N}\left(\hat{\alpha}^{N}\right)\right\}} & =\frac{1}{1+s_{i}} \\
\frac{\bar{\alpha}-\hat{\alpha}_{i}^{S}}{\left[1+\hat{\alpha}_{i}^{S}\right]\left\{1+2 \hat{\alpha}_{i}^{S}-2\left[1+\hat{\alpha}_{i}^{S}\right] m^{N}\left(\hat{\alpha}^{N}\right)\right\}} & =1 .
\end{aligned}
$$

It is easy to show that the left-hand side of both equations decreases in $\hat{\alpha}_{i}$. Since $s_{i}$ is positive, this implies that $\hat{\alpha}_{i}^{B}>\hat{\alpha}_{i}^{S}$. In other words, strategic delegation with side payments is more pronounced than in the case without side payments. The reason is that strategic delegation is now aimed at a more efficient transfer mechanism - sidepayments - instead of misusing the migration decision as a transfer mechanism and 
thereby incurring efficiency losses as in the previous subsection. ${ }^{16}$ We can summarize our results as follows:

Proposition 3 Coordination in the determination of policy towards refugees is desirable, but coordination with side payments between countries turns out to be less efficient than coordination without side-payments, i.e.

$$
m_{i}^{N}\left(\hat{\alpha}^{N}\right)<m_{i}^{S}\left(\hat{\alpha}^{S}\right)<m_{i}^{B}\left(\hat{\alpha}^{B}\right)<m_{i}^{U}(\bar{\alpha})
$$

In other words, either form of coordination is better than the non-cooperative outcome because coordination leads to the internalization of the cross-country spill-overs. Comparing different degrees of coordination, we see that less is more: The outcome without side-payments is more efficient than the result with cost sharing because the strategic delegation effect is not as severe. ${ }^{17}$ It is still present, however, so that even coordination without side-payments does not achieve the first best outcome.

\section{Asymmetric Countries}

So far we have considered the case of two symmetric countries. In reality, countries are heterogenous and it is natural to ask to what extent the main results of our analysis carry over even if we allow for differences between countries. Out of the many possible forms of heterogeneity, we focus on different average attitudes towards asylum seekers. Without loss of generality, we assume that $\bar{\alpha}_{2}>\bar{\alpha}_{1}$. To simplify matters and maintain tractability, we limit the analysis to the case where only the positive spill-overs of the warm glow apply $(\lambda=1)$. Individual utility then takes the following form:

$$
U_{i}\left(\alpha_{i}, m\right)=\left[1+\alpha_{i}\right]\left[m_{i}+m_{-i}\right]+\ln \left(1-m_{i}\right) .
$$

\footnotetext{
${ }^{16}$ This result is reminiscent of Wilson (1990) who shows that the availability of a more efficient policy instrument can lead to a less efficient equilibrium because the efficient instrument is used more extensively.

${ }^{17}$ One may wonder why the two countries would consider side-payments at all, since these turn out to lead to a welfare inferior outcome. We are implicitly assuming that politicians cannot commit to not use such payments. This assumption is supported by the fact that the use of side-payments is a prominent feature of the current political debate.
} 
The utilitarian optimum now involves the following immigration levels:

$$
m_{1}^{U}(\bar{\alpha})=m_{2}^{U}(\bar{\alpha})=\frac{1+\bar{\alpha}_{1}+\bar{\alpha}_{2}}{2+\bar{\alpha}_{1}+\bar{\alpha}_{2}}
$$

Note that the optimum implies the same number of asylum seekers in both countries, even though preferences differ, because this allocation equalizes marginal costs.

Consider next the non-cooperative case without policy coordination. Proceeding by backward induction, as before, we can derive the following immigation levels that are chosen by the respective elected representative:

$$
m_{i}^{N}\left(\hat{\alpha}_{i}\right)=\frac{\hat{\alpha}_{i}}{1+\hat{\alpha}_{i}}
$$

In the election stage, the median voter chooses to represent the country herself $\left(\hat{\alpha}_{i}=\right.$ $\bar{\alpha}_{i}$ ) implying that in this context we do not see any strategic delegation. ${ }^{18}$ We have therefore established the following series of inequalities:

$$
m_{1}^{N}\left(\bar{\alpha}_{1}\right)<m_{2}^{N}\left(\bar{\alpha}_{2}\right)<m_{i}^{U}(\bar{\alpha})
$$

In other words, the migration level in the less welcoming country is lower than in the more supportive country. Furthermore, both levels fall short of the utilitarian optimum. This implies an additional source of inefficiency as the marginal costs are no longer equalized.

\subsection{Policy Coordination without Cost Sharing}

We now turn to the case of policy coordination but exclude for the time being the possibility of cross-country transfers. As in Section 5.1, the two parties - by way of Nash bargaining — seek to maximize $N=s_{1} \cdot s_{2}$, where the surplus from coordination now takes the form:

$$
s_{i}=\left[1+\hat{\alpha}_{i}\right]\left[m_{1}+m_{2}\right]+\ln \left(1-m_{i}\right)-U_{i}\left(\hat{\alpha}_{i}, m^{N}\left(\hat{\alpha}^{N}\right)\right) .
$$

\footnotetext{
${ }^{18}$ This is due to our simplifying assumption of $\lambda=1$, not to the asymmetry.
} 
The corresponding first order conditions are:

$$
\left[1+\hat{\alpha}_{i}-\frac{1}{1-m_{i}}\right] s_{-i}+\left[1+\hat{\alpha}_{-i}\right] s_{i}=0
$$

From these first order conditions we can derive (see the appendix for the derivation) the effect of a marginal change in the identity of the representative $\left(\hat{\alpha}_{i}\right)$ on the policies $\left(m_{i}^{B}\right)$ decided in the second stage:

$$
\begin{aligned}
\frac{d m_{i}^{B}}{d \hat{\alpha}_{i}} & =\frac{s_{-i}^{2}\left(2+s_{-i}-2 s_{i}\left[1-m_{i}^{B}\right]\left[1+\hat{\alpha}_{-i}\right] / s_{-i}+\left[1+\hat{\alpha}_{-i}\right] \Delta m^{B}\right)}{s_{i}\left[1-m_{i}^{B}\right]^{2}|H|} \\
\frac{d m_{-i}^{B}}{d \hat{\alpha}_{i}} & =\frac{s_{-i}^{2}\left(2+s_{i}-2\left[1-m_{i}^{B}\right]\left[1+\hat{\alpha}_{i}\right]-\left[1+\hat{\alpha}_{i}\right] \Delta m^{B}\right)}{s_{i}\left[1-m_{i}^{B}\right]^{2}|H|} .
\end{aligned}
$$

where $\Delta m^{B}=\left(m_{1}^{B}-m_{1}^{N}\right)+\left(m_{2}^{B}-m_{2}^{N}\right)$ and the determinant $|H|>0$. Turning to the election stage, the first order condition of the median voter in country $i$ takes the following form:

$$
\left[1+\bar{\alpha}_{i}\right]\left[\frac{d m_{i}^{B}}{d \hat{\alpha}_{i}}+\frac{d m_{-i}^{B}}{d \hat{\alpha}_{i}}\right]=\frac{d m_{i}^{B} / d \hat{\alpha}_{i}}{1-m_{i}^{B}} .
$$

Inserting from (35) and (36) yields

$$
\left[\bar{\alpha}_{i}-\hat{\alpha}_{i}^{B}\right]\left[2+s_{i}+s_{-i}\right]=\left[\hat{\alpha}_{-i}^{B}-\hat{\alpha}_{i}^{B}\right]\left(s_{i}-\left[1+\bar{\alpha}_{i}\right] \Delta m^{B}\right)+\frac{\left[1+\hat{\alpha}_{-i}^{B}\right] \Delta m^{B}}{1-m_{i}^{B}}
$$

It follows from the above equations, that $\hat{\alpha}_{1}^{B} \neq \hat{\alpha}_{2}^{B}$. To see this suppose they were the same. Then the right hand side of the two equations would be the same, but not the left hand side, which is a contradiction. Under standard stability assumptions, it can further be shown that $\hat{\alpha}_{2}>\hat{\alpha}_{1}$, which is intuitively plausible. It follows that $m_{1}^{B}\left(\hat{\alpha}^{B}\right) \neq m_{2}^{B}\left(\hat{\alpha}^{B}\right)$. Note the significance of this result, as it implies that similarly to the non-cooperative case the allocation of asylum seekers is asymmetric and hence inefficient because marginal costs differ.

In addition, it follows from (38) that if $\hat{\alpha}_{i}^{B}$ and $\hat{\alpha}_{-i}^{B}$ are sufficently close together (i.e. $\left|\hat{\alpha}_{i}-\hat{\alpha}_{-i}\right|$ is sufficiently small) we again have strategic delegation, that is, a representative with a lower preference for immigration than the median. This result of our symmetric model thus carries over to the asymmetric case - as long as the 
countries are not too different.

\subsection{Policy Coordination with Cost Sharing}

Finally, we consider the situation where side-payments are possible. Solving backwards, the solution of the second stage has to maximize $\sum_{j} s_{j}$. This leads to the following policies:

$$
m_{i}^{S}(\hat{\alpha})=\frac{1+\hat{\alpha_{1}}+\hat{\alpha_{2}}}{2+\hat{\alpha_{1}}+\hat{\alpha_{2}}} .
$$

From this it follows that $m_{1}^{S}(\hat{\alpha})=m_{2}^{S}(\hat{\alpha})$, i.e. marginal costs are equalized which means that transfers are effective at eliminating the inefficiency pointed out above. We thus see that in the asymmetric case the possibility of side-payments also has a beneficial, efficiency enhancing role that mitigates its adverse effect on strategic delegation. The actual monetary transfer paid by country 2 to country 1 amounts to:

$$
Z^{S}\left(\hat{\alpha}, m^{S}(\hat{\alpha})\right)=\frac{\left[\hat{\alpha}_{2}-\hat{\alpha}_{1}\right] \Delta m^{S}+\ln \left(1-m_{1}^{N}\right)-\ln \left(1-m_{2}^{N}\right)}{2}
$$

where $\Delta m^{S}=\left(m_{1}^{S}-m_{1}^{N}\right)+\left(m_{2}^{S}-m_{2}^{N}\right)$. Note that the transfer increases in the difference between the two representatives' preferences for immigration. Following the same procedure as before, we can derive the following equilibium condition for the election stage of the model:

$$
\frac{2\left[\bar{\alpha}_{i}-\hat{\alpha}_{i}^{S}\right]}{\left[2+\hat{\alpha}_{1}^{S}+\hat{\alpha}_{2}^{S}\right]^{2}}=\frac{\Delta m^{S}}{2} .
$$

This condition is equivalent to the corresponding condition in the symmetric case. We see from (41) that, measured by the difference between $\bar{\alpha}_{i}$ and $\hat{\alpha}_{i}$, the degree of strategic delegation is the same for both countries. Clearly then, the representative of country 2 has a higher preference for immigration than his counterpart in country 1. Furthermore, we see from (40) that the side-payment is positive, i.e. country 2 pays country 1 to accept more asylum seekers. 


\section{Conclusion}

While opinion polls show that EU citizens prefer their countries to retain national immigration policies, many political observers have argued in favor of policy coordination, especially where asylum seekers are concerned. On the one hand, the ever increasing restrictiveness of national EU policies has prompted authors like Noll (2000) to demand that a 'race to the bottom' be avoided. On the other, Hatton (2004) and Hatton and Williamson (2004) advance the argument that EU citizens share an altruistic attitude towards 'real' refugees. As a consequence, coordination is called for in order to internalize inter-jurisdictional spill-overs. Others have gone a step further and suggested even deeper coordination in the form of monetary cost sharing to compensate those members that are particularly popular destinations for refugees.

In this paper, we model policy towards asylum seekers and refugees along public good lines. However, whereas previous work has focused on welfare maximizing arguments, we move beyond the perspective of a benevolent social planner and focus on the democratic process that determines policy. Comparing the non-cooperative, decentralized outcome to cases of differing degrees of coordination, interesting results emerge. On the one hand, coordination is desirable, even when we take into account the political process, since it leads to an internalization of the inter-jurisdictional spill-overs. On the other, when comparing different degrees of coordination, we show that cost sharing in the form of monetary transfers across countries can make matters worse. In fact, while coordination with transfers is still better than the noncooperative outcome, it is dominated in the symmetric setup by the lesser form of coordination without such side-payments. The availability of side payments exacerbates the strategic delegation effect and leads countries to accept an inefficiently low number of refugees. This result suggests that caution is in order when considering the coordination of policies towards asylum seekers and refugees. While some degree of cooperation is desirable, excessive coordination that involves cost sharing can be less efficient. Even though our model is tailored to fit the case of involuntarily displaced individuals, the argument is clearly applicable to more general settings. As long as workplace regulations are imperfectly enforced and immigrants in the EU common 
market give rise to cross-country spill-overs, a similar argument can be made against 'excessive' coordination of migration policy.

To the best of our knowledge, the current paper is the first to rigorously model the political determination of asylum policies. As such, it employs a number of simplifying assumptions that could be relaxed. By introducing asymmetric preferences towards asylum seekers we take a first step in this direction. Allowing for additional asymmetries could be important in assessing the more general effects of policy coordination. Similarly, explicitly modelling more than two countries would allow us to achieve a better understanding of the dynamics aspects of the formation of coalitions in the bargaining game. While these are clearly very interesting questions, we leave them for further research.

\section{Appendix}

\subsection{Symmetric Case}

This appendix derives $d m_{i}^{B} / d \hat{\alpha}_{i}$ and $d m_{-i}^{B} / d \hat{\alpha}_{i}$ for the bargaining equilibrium without side-payments. The first-order condition for $m_{i}^{B}$ as given by (14) is $N_{m_{i}}=0$. The first-order condition for $m_{-i}^{B}$ is $N_{m_{-i}}=0$. From totally differentiating these equations, we obtain

$$
\begin{aligned}
\frac{d m_{i}^{B}}{d \hat{\alpha}_{i}} & =\frac{-N_{m_{i} \hat{\alpha}_{i}} N_{m_{-i} m_{-i}}+N_{m_{-i} \hat{\alpha}_{i}} N_{m_{i} m_{-i}}}{N_{m_{i} m_{i}} N_{m_{-i} m_{-i}}-N_{m_{i} m_{-i}} N_{m_{-i} m_{i}}} \\
\frac{d m_{-i}^{B}}{d \hat{\alpha}_{i}} & =\frac{-N_{m_{-i} \hat{\alpha}_{i}} N_{m_{i} m_{i}}+N_{m_{i} \hat{\alpha}_{i}} N_{m_{-i} m_{i}}}{N_{m_{i} m_{i}} N_{m_{-i} m_{-i}}-N_{m_{i} m_{-i}} N_{m_{-i} m_{i}}}
\end{aligned}
$$


Departing from the symmetric equilibrium $\left(\hat{\alpha}_{i}=\hat{\alpha}_{-i}\right.$ and $\left.s_{i}=s_{-i}\right)$, the respective terms in (42) and (43) can be derived as

$$
\begin{aligned}
N_{m_{i} m_{i}} & =-2\left[1+\hat{\alpha}_{i}\right]^{2}\left\{2 s_{i}\left[1-2 \lambda+2 \lambda^{2}\right]+[1-2 \lambda]^{2}\right\}=N_{m_{-i} m_{-i}}, \\
N_{m_{i} m_{-i}} & =-2\left[1+\hat{\alpha}_{i}\right]^{2}\left\{4 s_{i} \lambda[1-\lambda]-[1-2 \lambda]^{2}\right\}=N_{m_{-i} m_{i}}, \\
N_{m_{i} \hat{\alpha}_{i}} & =s_{i}+2\left[1+\hat{\alpha}_{i}\right][2 \lambda-1]\left[m_{i}^{B}(\hat{\alpha})-m_{i}^{N}\left(\hat{\alpha}^{N}\right)\right] \\
N_{m_{-i} \hat{\alpha}_{i}} & =s_{i}-2\left[1+\hat{\alpha}_{i}\right][2 \lambda-1]\left[m_{i}^{B}(\hat{\alpha})-m_{i}^{N}\left(\hat{\alpha}^{N}\right)\right] .
\end{aligned}
$$

Inserting these equations into (42) and (43) and rearranging yields

$$
\begin{aligned}
\frac{d m_{i}^{B}}{d \hat{\alpha}_{i}} & =\frac{\left[1+s_{i}\right][2 \lambda-1]+2\left[1+\hat{\alpha}_{i}\right]\left[m_{i}^{B}(\hat{\alpha})-m_{i}^{N}\left(\hat{\alpha}^{N}\right)\right]}{4[2 \lambda-1]\left[1+\hat{\alpha}_{i}\right]^{2}\left[1+s_{i}\right]} \\
\frac{d m_{-i}^{B}}{d \hat{\alpha}_{i}} & =\frac{\left[1+s_{i}\right][2 \lambda-1]-2\left[1+\hat{\alpha}_{i}\right]\left[m_{i}^{B}(\hat{\alpha})-m_{i}^{N}\left(\hat{\alpha}^{N}\right)\right]}{4[2 \lambda-1]\left[1+\hat{\alpha}_{i}\right]^{2}\left[1+s_{i}\right]} .
\end{aligned}
$$

\subsection{Asymmetric Case}

As in the symmetric case, the equations determining the marginal influence of $\hat{\alpha}_{i}$ on the immigration levels can be derived from the first order conditions and are identical to equations (42) and (43) above, with $N_{m_{i}}=0$ given by equation (34). From (34) the following equations can be derived:

$$
\begin{aligned}
N_{m_{i} m_{i}} & =-\frac{s_{-i}}{\left[1-m_{i}\right]^{2}}-2\left[1+\hat{\alpha}_{-i}\right]^{2} s_{i} / s_{-i}, \\
N_{m_{i} m_{-i}} & =2\left[1+\hat{\alpha}_{i}\right]\left[1+\hat{\alpha}_{-i}\right], \\
N_{m_{-i} m_{-i}} & =-\frac{s_{i}}{\left[1-m_{-i}\right]^{2}}-2\left[1+\hat{\alpha}_{i}\right]^{2} s_{-i} / s_{i}, \\
N_{m_{i} \hat{\alpha}_{i}} & =s_{-i}+\left[1+\hat{\alpha}_{-i}\right] \Delta m^{B}, \\
N_{m_{-i} \hat{\alpha}_{i}} & =s_{-i}-\left[1+\hat{\alpha}_{i}\right] \Delta m^{B} s_{-i} / s_{i} .
\end{aligned}
$$

Inserting these equations, employing (34), and rearranging yields (35) and (36), with $|H| \equiv N_{m_{i} m_{i}} N_{m_{-i} m_{-i}}-N_{m_{i} m_{-i}} N_{m_{-i} m_{i}}>0$. 


\section{References}

Besley, T. and S. Coate (1997). An economic model of representative democracy. Quarterly Journal of Economics, 85-114.

Besley, T. and S. Coate (2003). Centralized versus decentralized provision of local public goods: a political economy approach. Journal of Public Economics 87, $2611-37$.

Boeri, T., G. Hanson, and B. McCormick (Eds.) (2002). Immigration policy and the welfare system. Oxford: Oxford University Press.

Hatton, T. J. (2004). Seeking asylum in Europe. Economic Policy 38, 5-62.

Hatton, T. J. and J. G. Williamson (2004). Refugees, asylum seekers and policy in Europe. mimeo, Harvard University.

Lorz, O. and G. Willmann (2005). On the endogenous allocation of decision powers in federal structures. Journal of Urban Economics 57, 242-257.

Luedtke, A. (2005). European integration, public opinion and immigration policy: Testing the impact of national identity. European Union Politics 6 .

Noll, G. (2000). Negotiating Asylum: The EU Acquis, extraterritorial protection and the common market of deflection. The Hague: Martinus Nijhoff.

Osborne, M. J. and A. Slivinski (1996). A model of political competition with citizen-candidates. Quarterly Journal of Economics 111(1), 65-96.

Segendorff, B. (1998). Delegation and threat in bargaining. Games and Economic Behavior 23, 266-283.

UNHCR (2003). 2003 Global refugees trends. Geneva: United Nations High Commission on Refugees.

Willmann, G. (2004). Why legislators are protectionists: The role of majoritarian voting in setting tariffs. http://ssrn.com/abstract $=564587$.

Wilson, J. D. (1990). Are efficiency improvements in government transfer policies self-defeating in political equilibrium? Economics and Politics 2, 241-58. 